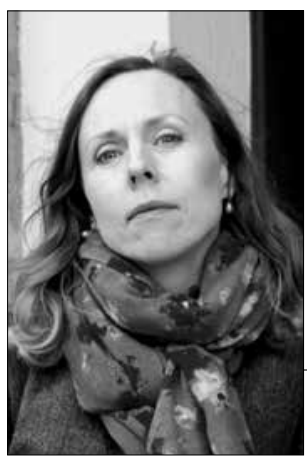

https://doi.org/10.24101/logos.2016.08

Gauta 20161118

REDA ŠATŪNIENE

Šiaulių universitetas, Lietuva

Šiauliai University, Lithuania

\title{
TARP GYVENIMO STILIAUS IR SVEIKATOS: PAKEISTOS (NEIPRASTOS) SĄMONĖS BÜSENOS KAIP ALTERNATYVAUS GYDYMO(SI) SUVOKIMAS
}

\author{
Between Lifestyle and Health: Non-Ordinary (Changed) \\ States of Consciuoseness as Practice of (Self)Healing
}

SUMMARY

This publication analyzes the cultural meanings of 'health', and 'healing.' It focuses on the point of view towards 'health', 'illness' (as an opposition to 'health'), and (self) healing by individuals who practice various alternative treatment systems. According to the latest author's empirical study (2015-2016) one's approach to 'health', 'illness', and 'healing' is closely associated with a person's promoted lifestyle, and worldview. Based on theoretical, and empirical research, the publication examines, how cultural attitudes encourage individuals to choose alternative ways of healing, such as the experiences of non-ordinary (changed) states of consciuoseness (using psychoactive substances or without), which, by research participants, are interpreted as a kind of (self) healing. The paper tries to find out how these choices are associated with individual lifestyles and the understanding of 'health', and self-healing.

\section{SANTRAUKA}

Publikacijoje analizuojamos "sveikatos" ir "gydymo(si)" kultūrinės reikšmės bei alternatyvias gydymo sistemas praktikuojančių asmenų požiūris į "sveikatą", analizuojamas individualus "sveikatos", "ligos" (kaip opozicijos „sveikatai“) ir "gydymo(si)“ prasmių konstravimas. Naujausiais autorés empirinio tyrimo duomenimis (2015-2016) pagrindžiama, kad požiūris ì sveikatą, ligą ir gydymąsi glaudžiai susijęs su asmens propaguojamu gyvenimo stiliumi, pasaulěžiūra. Remiantis originaliu empiriniu tyrimu analizuojama, kokios kultūrinės nuostatos skatina asmenis rinktis alternatyvius gydymo(si) būdus, pakeistų, neįprastų sąmonès 
būsenų (naudojant psichoaktyvias ${ }^{1}$ medžiaga arba be jų) patyrimus, kuriuos pateikèjai interpretuoja kaip tam tikrą gydymo ar savigydos² procesą. Tiriama, kaip šie pasirinkimai susiję su "sveikatos" ir "gydymo(si)" supratimu ir asmenų kultivuojamu gyvenimo stiliumi.

\section{IVADAS}

Straipsnyje aptariamos kultūrologinès, antropologinès, etnologinès „sveikatos“ („sveiko būvio“), "ligos“ ir "gydymo(si)“ sampratos. "Gydymas" ir "gydymasis" publikacijoje traktuojamas taikant kultūrologinę ir etnologinę prieigą: "gydymas" traktuojamas ne kaip medikamentinis konvencinès ${ }^{3}$ medicinos gydymo procesas, bet kaip viską apimanti sveiko fizinio ir psichinio būvio siekiamybè. Itvairios "gijimo" procesus skatinančios veiklos gali būti ìvairios: netradicinè, etno, liaudies medicina ar net su ezoterinemis praktikomis susiję gydymo(si) būdai. Artimiausias terminas - anglų k. „,healing“, kumuliuojantis platų veiklų, skatinančiu išgijima, pasveikimą, visišką pagydymą, spektrą.

Publikacijoje, remiantis teoriniais ir empiriniais tyrimais, analizuojamos sociokultūrinès "sveikatos", ,sveiko būvio", "ligos" ir "gydymo(si)“ sampratu konstrukcijos, kultūrinès reikšmès, išsamiau tiriamos pakeistos ${ }^{4}$, neiprastos sąmonès būsenos ir patirtys kaip vienas iš galimų alternatyvaus gydymo(si) būdų tam tikruose sociokultūriniuose visuomenès sluoksniuose. Straipsnio tikslas - išanalizuoti alternatyvias gydymo sistemas palaikančiu asmenu požiūrị i neipprastas sąmonès būsenas kaip tam tikrą gydymo(si) būdą, ši požiūrį siejant su individualia pasaulěžiūra ir gyvenimo stiliumi.

Publikacija pratęsia ankstesnius autorès alternatyvių kultūrų ir gyvenimo būdo studijas doktorantūros ${ }^{5}$ ir podoktorantūriniu ${ }^{6}$ laikotarpiais, papildydama jas nūdienos sociokultūrinèms grupėms priklausančiu narių alternatyvių gydymo(si) traktuočiu ir praktiku tyrimais. Teorinio ir empirinio tyrimo duomenimis pagrindžiama, kad požiūris i sveikatą ligą ir gydymąsi yra glaudžiai susijęs su asmens pasaulezžiūra ir gyvenimo būdu: analizuojama, kokios kultūrinès nuostatos skatina asmenis rinktis alternatyvius gydymo(si) būdus, kokiu būdu asmeninės vertybės gali nulemti asmens požiūrị i „,sveikatą", „ligą“ ir gydymo(si) praktiku pasirinkimą ir pan.

\section{VAKARY̨ IR LIETUVOS ETNOMEDICINOS TYRIMŲ KONTEKSTAI}

Lietuvos kontekste medicininès antropologijos tyrimus atliko R. Trimakas, R. Petkevičius, kiti. Trimakas ${ }^{7}$ monografijoje apie XIX a. pab.-XX a. pr. liaudies mediciną nagrinëjo iš etnologijos ir folkloristikos perspektyvos, V. Gribauskaite publikacijoje „Ligų etiologijos Rytų Lie- tuvos ir Vakarų Baltarusijos kaime XIX a. pabaigoje-XX a. pirmojoje pusejje ${ }^{\prime 8}$ aiškinasi tikejimus dèl ligu priežasčiu, egzistavusius prieš gerą šimtmeti. R. Petkevičius tyrinëjo etnopsichiatrijos apraiškas: studijoje „Nerviniai sutrikimai ir ju gydymas Užpaliu apylinkių XX-XXI a. 
tradicinejje medicinoje ${ }^{\prime \prime 9}$ pristato atliktus lietuvių liaudies medicinos tyrimus - augalų rūšis, žolelių rinkimą ir naudojimą etnopsichiatrijos srityje.

Pakeistu, neiprastų sąmonès būsenų tyrimai lietuviškame kontekste iš dalies siejami su etnologiniais „naujojo šamanizmo" tyrinejimais, kuriuose labiau fokusuojamasi ị religini aspektą (E. Aleknaitė, „Šamaniški elementai baltų religinèje tradicijoje“, 2008), tačiau neaptikta akademiniu publikacijų, kuriose būtu fokusuojamasi i pakeistas, neiprastas sąmonès būsenas būtent kaip i tam tikrą alternatyvios medicinos (gydymo ar savigydos) forma, kurios praktikavimas glaudžiai susijęs su asmens gyvenimo būdu, stiliumi, gyvenimo filosofija.

Vakarų šalyse pakeistu, neịprastų sąmonès būsenų antropologiniai ir etnologiniai tyrimai turi gilesnes šaknis jau vien dèl susiklosčiusių istorinių aplinkybių: antropologinių senụjų kultūrų tikèjimu tyrimai Vakaruose buvo atliekami dar septintajame dešimtmetyje, pvz., buvo tiriamos tokios praktikos kaip pejoto ar ajachuaskos vartojimo ritualai Amerikos indènu bendruomenèse. Pakeistų (neịprastų) sąmonès būsenų tyrimai gana išpopuliarèjo antropologams pradejus tyrinèti šamaniškas kultūras ${ }^{10}$, kur šamaniška ekstazė, pakeistų, neíprastų sąmonès būsenų kultivavimas turëjo esminę reikšmę sprendžiant aktualius bendruomenès klausimus. Transas, ekstazė ar kitos neiprastos sąmonès būsenos buvo praktikuojamos gydymo ir šamanu mokymu procesuose.

Winkelmanno teigimu, šamaniškos transo sukèlimo technikos „stimuliuoja autonominę nervų sistema, svarbiausius sąmonės procesus ir asocijuojamus emocinius bei prisirišimo mechanizmus: atsipalaidavima, pasąmonès turinio integravimą i sąmonę, stimuliuoja endogeninius gijimo procesus ${ }^{\text {“11 }}$ - taigi, akcentuoja terapinį pakeistų, neịprastų sąmonès būsenų poveiki, tai sieja su serotonino ${ }^{12}$ ir kitu natūralių cheminių medžiagų poveikiu.

Pakeistų (neịprastų) sąmonès būsenų kultūrologinius tyrimus galima priskirti sąmonès antropologijos sričiai, kuri tyrinejja magišku reiškinių, tikejimų supratimus („magiškoji sąmonè") ìvairiuose kultūriniuose ir laiko kontekstuose ${ }^{13}$. Sąmonè iqvairiomis formomis ir būdais dalyvauja asmens kasdieniame gyvenime organizuodama fizinès ir psichinès veiklos procesus, taip pat daro įtaką gydymo ir gydymo(si) eigai.

\section{TARP GYVENIMO BŪDO IR GYDYMO(SI)}

Remiantis Larsono (2006) ir Winkelmanno (2009) alternatyvios medicinos apibrèžtimis, alternatyviam gydymui gali būti priskiriamos ne tik mūsų kultūriniam suvokimui egzotiškos, bet ir tradiciškai suvokiamos veiklos, traktuojamos kaip iprastos kasdienès praktikos: ivairiu rūšiu sportas (bẻgimas, važinèji- mas dviračiu), tam tikrų produktu atsisakymas (vegetarizmas, veganizmas) ${ }^{14}$ ar badavimas; pasivaikščiojimai parke, žolelių arbatos gèrimas, specialios dietos; gydymas kristalais, akupunktūra, hipnozé, dvasinis ir energetinis gydymas, aromaterapija, spalvu terapija ${ }^{15}$ ir pan. Minètos ir panašios praktikos neretai labiau 
asocijuojamos su "gyvenimo stiliaus", "laisvalaikio" ar "pasirinkimų" (angl. "taste“) grupèmis / subkultūromis ir analizuojamos būtent tais aspektais. Anot Winkelmanno, gydymo(si) procesas visuomet vyksta tam tikroje kultūrinëje sistemoje, o jo tiekejjai ir gavejai priklauso subkultūroms, t. y. sociokultūrinèms grupėms ${ }^{16}$, kurioms būdingos savitos tarpusavio bendravimo, elgesio, išvaizdos normos, požiūriai ir nuostatos.

Asmens ir visuomenès sveikatą nulemia virtinè kultūriniu, socialinių ir ekonominiu faktorių: individualus elgesys, mityba, aplinkos sąlygos, asmeniniai fiziniai rodikliai, visuomenès palaikymas, materiali pagalba ${ }^{17}$. Galimybe išvengti tam tikrų ligu arba pasveikti yra susijusi su kultūriniais įsitikinimais, tikejjimais, ìprastomis kasdienèmis praktikomis, požiūriais ir nuostatomis ${ }^{18}$.

Kultūriniai faktoriai yra vieni esminiu kalbant apie sveikatos, ligos ir sveiko būvio supratimus. Tokiomis sąlygomis aktualu tyrinèti šiandieninèje kultū- roje vyraujančius "sveikatos", "ligos" supratimus šitaip praplečiant "gydymos(si)" kultūrinę sampratą ar galimai integruojant šiuos duomenis iz konvencionalias medicinos sistemas.

Liga, jog gydymas, eiga taip pat konstruojami ir sociokultūriniais aspektais: egzistuoja specifinè medicinos kalba (žargonas); specifinis ligos įvardijimo, klasifikavimo ir paaiškinimo būdas; gydytojo - paciento santykiai, šiuolaikiniai gydymo procesa lydintys ritualai ${ }^{19}$ ir pan. Winkelmannas pažymi, kad etnomedicina turi būti analizuojama taip pat, kaip ir politinè ar religinè sistema, kalba ar kitos simbolinès sistemos ${ }^{20}$ : pvz., oficialioji biomedicina istatymais numatyta tvarka sprendžia, kurie vaistai pacientui bus prieinami gydant atitinkamą ligą o ịstatymais apibrèžtos (suteiktas kodas) ligos (ypač „naujos“, sudètingai diagnozuojamos ir plačiojoje visuomeneje ne itin pripažistamos ${ }^{21}$ ) sukuria ir kultūrines normas, mat šis formalus matas numato, kada žmogus laikomas sergančiu, kada - ne.

\section{"SVEIKATOS", "LIGOS" IR "GYDYMO(SI)" SAMPRATOS SKIRTINGUOSE KULTÜRINIUOSE KONTEKSTUOSE}

Vakarietiškoje medicinos paradigmoje sveikata suvokiama kaip kokybiškas fiziniu ir psichinių žmogaus kūno sistemų funkcionavimas. Alternatyvios sveikatos sampratos dažniausiai ją laiko tam tikra a priori egzistuojančia tvarka, harmonija. Pvz., Amerikos indènų sveikatos samprata remiasi keturiu sferų (kūnas, protas, dvasia, emocijos) derme: ligą sukelia šiu sferų išbalansavimas. Ajurvedoje panašiai: išskiriamos trys došos (vata, kapha ir pita), kurių kiekviena reprezentuoja tam tikrą specifinį disbalansą žmogaus kūno struktūroje. Kinų medicinoje pripažįstamas ,jing ir jang“ harmonijos principas. Sveikatos samprata apima fizinę, psichinę ir socialinę gerovę, galimybes pagal savo norą dalyvauti šeimos, bendruomenès ar darbiniuose reikaluose, galimybę prisitaikyti prie kintančių sąlygų ${ }^{22}$, arba tiesiog gerą savijautą. Winkelmanno teigimu, biologinès medicinos kontekste "sveikatos" samprata tarp gydytoju ir pacientų ski- 
riasi: profesinis gydytojų ruošimas „,sveikatos" sampratą ispraudžia į siaurus simptomu diagnostikos ir ju gydymo strategijų rèmus, o pacientai „sveiką būvị “ supranta kitaip; dažniausiai - kaip gerovęę, ne vien simptomų pašalinimą.

Taigi „sveikatos", „ligos", o atitinkamai - ir gydymo strategijos priklauso nuo tradicijų, tikëjimu, mentaliteto, susiformavusios pasaulèžiūros. Priklausomai nuo sveikatos sampratos, požiūrio į žmogaus prigimti, lokalias tradicijas priklauso ir parenkamas (ar pasirenkamas) gydymo(si) būdas. O tai nurodo, kad gydymo(si) traktuočiu ir praktikų spektras gali būti labai individualus, platus.

\section{PAKEISTŲ, ARBA NEIPRASTŲ, SĄMONĖS BŪSENŲ REIKŠMĖ (IR PRAKTIKOS) GYDYMO PROCESUOSE}

Pakeistu (angl. ",changed“, ,"altered“), neiprastų (angl. "non-ordinary“) sąmonès būsenų reikšmè gydymo procese žinoma nuo seniausių laikų: žyniai, šamanai gydydavo esant pakitusiai sąmonès būsenai ${ }^{24}$; pripažistama, kad gydomaji poveikị turi meditacija, gili koncentracija, malda, ir pan.

Medicinos antropologo Winkelmanno teigimu, pakeistos sąmonès būsenos veikia kaip integralus sąmonès modelis, aktyvuoja izvairius savasties ir emocinius aspektus, veikia simpatinę nervų sistemą. Ilgalaikio dainavimo, būgnų mušimo, šokio metu ir pan. simpatinė nervų sistema tiek išvarginama, kad ją užvaldo kita - parasimpatine $\dot{e}^{25}$. Šis procesas sukelia matomus vaizdinius, vizijas, gali būti jaučiama, kad dvasia palieka kūną, vyksta spontaniškos konvulsijos: smegenyse vyksta atitinkami procesai, sąlygojantys dramatiškus tapatumo, asmenybès, elgesio, emociju pokyčius ${ }^{26}$.

Pakeistą sąmonę galima patirti meditacininiu praktiku - satori, nušvitimo, nirvanos, vidinès palaimos ir pan. - metu. Tada dažniausiai orientuojamasi $\mathfrak{i}$ asmens vidu, siekiama sąmoningai fiksuoti pokyčius, kontroliuoti prota, troš- kimus. Meditacijos metu taip pat patiriami mistiniai išgyvenimai, pvz., žmogaus - gamtos - kosmoso jungtis ir pan. Šios meditacinès būsenos gali būti pasiekiamos giedojimo, nemigos, badavimo, kitokių mitybos praktikų ar sensorinių apribojimu metu $^{27}$.

Psichologijoje psichoaktyviu medžiagu $\left(\right.$ LSD $\left.^{28}\right)$ naudojimas vadinamas „psicholitiniu“ požiūriu - kada atitinkami šių medžiagu kiekiai naudojami psichoterapiniuose užsièmimuose. Šio preparato naudojimas itin pagreitindavo psichoterapinių seansu greiti / efektyvuma, nes pašalindavo gynybinius emocinius blokus, ypač per katarsio (dèl psichoaktyvios medžiagos poveikio) patyrima, o tai itin pagreitindavo visą psichoterapijos procesąą. Vienas pasaulyje pripažintu žinomu gydytojų, psichiatras, klinikinès medicinos atstovas Stanislavas Grofas dar septintojo dešimtmečio pradžioje Čekijoje ir JAV inicijavo LSD terapijos metodą, kai gydant pacientą buvo naudojama pusiau sintetinè, penktojo dešimtmečio pradžioje Aleberto Hofmanno atrasta medžiaga. Ilgainiui šis terapijos metodas dèl „moralinès panikos" visuomenèje, kurią 
kèlè griaunantis LSD poveikis, neįsitvirtino psichoterapijoje, apsistota ties eksperimentine veikla. Priklausomybių ligu specialistas Michaelis Gosopas apgailestauja, kad tapo sudètinga „palaikyti racionalią diskusiją apie šio narkotiko galimą naudą“"30.

Kiek vèliau S. Grofas išrutuliojo vadinamojo "holotropinio" kvėpavimo technika, kai neipprastos sąmonės būsenos pasiekiamos nenaudojant psichoak- tyvių medžiagų. „Holotropinio“ kvèpavimo metu patiriami išgyvenimai turi terapini (emocijų paleidimo, išsilaisvinimo iš baimių ir pan.) poveiki. S. Grofo psichoterapinès technikos gana artimos šamaniškoms neịprastų sąmonès būsenų sukèlimo technikoms, tokioms kaip šokis, muzika, drama, humoras ar socialiniai ritualai, kurių metu, kaip teigiama, vyksta proto-kūno komunikacijos ir gydymo procesai ${ }^{31}$.

\section{EMPIRINIO TYRIMO METODOLOGIJA IR DUOMENYS}

Atliekant etnografini lauko tyrimą buvo taikoma etnografinio (antropologinio) tyrimo metodologija, kuri padeda kultūros ar meno fenomeną ištirti išsamiai, ypač - jei tai naujas, menkai tyrinètas sociokultūrinis reiškinys.

Buvo taikomi šie etnografinio tyrimo metodai: stebejimas, giluminiai interviu, diskusijos, neformalūs pokalbiai, atviru klausimų anketa, dokumentų analizè. Tyrimas buvo atliekamas 2015-2016 m. Kaune ir Vilniuje. Tyrimo dalyvių amžius 28-47 metai. Iš viso apklausta dešimt pateikèjų ${ }^{32}$. Giluminių interviu trukmè - apie 1-1,5 val. Interviu duomenys iššifruoti, koduoti, struktūruoti pagal iš vidaus kylančią problematika, pateikèju teikiamus reikšminius prioritetus ir tyrimui aktualias temas.

Pateikëjų apibrèžties kriterijus: sąmoningas alternatyvių gydymos(si) metodu praktikavimas, artikuliuotas savo sąmonès būsenos, ypač - pakeistos, neiprastos sąmonès kaip reikšmingos savasties (tapatumo) sudedamosios dalies stebejjimas ir fiksavimas, aiškus naudojamų alternatyviu gydymo(si) praktiku ivardijimas, jų reikšmingumas asmens gyvenimo pasirinkimuose.

\section{NEIPRASTŲ SAZMONĖS BÜSENŲ PATYRIMAS KAIP ALTERNATYVAUS GYDYMO(SI) SUVOKIMAS}

Per tyrimą buvo pastebèta, kad neįprastų sąmonès būsenų patyrimo siekiantys asmenys domëjosi savo psichika, sąmonès praplètimo galimybèmis (ne vien vartojant stimuliuojančias medžiagas), patys akcentavo savo siektiną tikslą - tapti geresniais žmonėmis, giliau suvokti vieta, kurioje gyvename (Žemę, aplinką), bent iš dalies nujausti priežastị, kodèl mes gimème šioje vietoje ir šiuo laiku. Per tyrimą buvo fiksuojamas gana viską apimantis susidomėjimas savęs pažinimo ir alternatyviosios medicinos metodais kaip priemonėmis susikurti geresni, komfortabilesni gyvenimo būdą. Su tuo susijusi literatūra dažnai nuveda 
i atitinkamą sociokultūrinę terpę, kurioje randami bendraminčiai.

Turimi empirinio tyrimo duomenys rodo, kad tyrimo dalyviai (asmenys, tikslingai praktikuojantys pakeistas arba neịprastas sąmonės būsenas (vartoja psichoaktyvias medžiagas ar pasiekia šias būsenas kitais būdais) gali būti traktuojami kaip užsiimantys tam tikra savęs gydymo - (su)gijimo, žaizdu (ne fizinių) užgydymo praktika. Užfiksuota, kad neiprastų sąmonès būsenų siekis (neretai siejamas su dvasiniais ieškojimais) tyrimo dalyviu traktuojamas kaip savotiškas terapinis - gydomasis ",savi-integracinis“ (remiamasi kai kuriu tyrimo dalyvių vartojama terminija) procesas. Pakeistas sąmonès būsenas tyrimo dalyviai traktavo kaip savo paslepptos dalies vidini integravima, energijos atgavimą, vidinès jègos atradima, vidini gydymo procesą. Fiksuojamas pozityvus požiūris, neįprastoje sąmonès būsenoje patirtu išgyvenimų prièmimas, gana plačiai apibrèžiama sveikatos kaip tam tikro komfortabilaus vidinio būvio sąvoka.

Ats.: - Nuostabi gydanti substancija. Kl.:

- O kaip tu supratai, kad tai gydanti...? Kas tai yra gydymas tau? [...] Ats.: - Po to aš jaučiuosi ramiau, drąsiau. [...] Tai nebuvo kaip kažkoks nušvitimas ar kas. Tai viskas daug paprasčiau. Tai toks atšviežinimas ivvyko (2016 rugsëjis, mot., 41 m.).

Pats neịprastos sąmonès būsenos patyrimo procesas apibūdinamas kaip tam tikros vidinès stiprybès reikalaujanti situacija, reikalinga atitinkamu psichoemocinių gebèjimų, valios.

Tai yra situacija, iš kurios tu negali pabègt. Tai atsiduri tokioje būsenoje, iš kurios negali pabègt. [...] Tu turi patirti ją.
Net jei nesijauti komfortabiliai [...]. Tau reikia priimti tai. Čia reikia stengtis, būti pasiryžus (mot., 42 m.).

Pastebèta, kad priežastis, paskatinusi siekti patirti neiprastą sąmonès būseną natūraliomis, psichoaktyviomis priemonėmis, buvo tarsi nulemta: neformaliu pokalbiu metu buvo teigiama, kad atsiranda vidinis poreikis, noras „atsinaujinti“. Verta akcentuoti, kad pakeistu sąmonès būsenų praktikavimas laikomas retu ịvykiu, kurio dažnai praktikuoti negalima: būsenos sureikšminamos kaip turinčios ypatingą poveiki, tad jų dažnas praktikavimas savotiškai devalvuotu jų sveikatinamą gydomają ar netgi sakralią prigimtį.

Paraleliai diskutuojama apie vartotojišką požiūrį i pakeistų sąmonès būsenų praktikavima, kuris nèra toleruojamas.

Visų pirma aš - šitą citatą būtinai pavartokit - tam, kad galètų žmonès, kurie mokosi, ar tie, kurie vartoja dèl "fun", arba vardan to, kad čia yra "kita“ ir eina i klubus, visų pirma yra sąmoningumas (akcentuoja žodi, - aut. past.). Žmogus subrendęs vidumi - [pauzè] širdis ir protas [rodo] - ir tada jisai galès atsakyti už save. Jei bus jis durnas [...] durnas pavartojo, durnas ir liks. [...]. Tai dèl tai visų pirma yra atsakomybè ir klausimas „ar aš tą patempsiu“ (vyr., $28 \mathrm{~m}$.).

Per tyrimą buvo akcentuota pakeistu, neiprastų sąmonès būsenų gydomoji galia, sakralioji šiu būsenų išgyvenimo pusé, bet pateikti ir tam tikri apribojimai: kada, kam ir kokiomis aplinkybèmis galima vartoti sąmonę keičiančias substancijas.

Ats.: - Tą daryti (tikslingai vartoti psichoaktyvias medžiagas, - aut. past.) reikia: 
pirma, gydymui, antra, bendravimui su alternatyviomis realybèmis, informaciniu lauku, pan. [...] tai kolektyvinè misterija. [...] Žmonès atitrūkę nuo gamtos, sakralumo, ir (dèl psichoaktyviu medžiagų, aut. past.) patirią tą dieviškuma, jis gali išgyvent tą sakralų momentą. Kad ir vakarèlį kur parūkęs, kur nepraejjęs dvasinių praktiku tu to negali patirti. Kl.: - Bet tai ten vakarèlio metu tai ką ten supranta, jei to dieviškumo neieško?... Ats.: - Net jei jis ir nežino, bet jis gali tą patirt, jam gali tą atvert, kažką paleist jam gali. Jame sujudins kažka, kad jam atsivers. [...] Tai [vartojimas psichoaktyvių medžiagų, - aut. past.] turi būti kvalifikuota, tada tai bus tikra, kitaip bus [...] [negera, neteisinga, aut. past.]. [...] Ir aišku, šios medžiagos negali būti vartojamos vaikų ar paaugliu, nes nežinai, gali kas nors ir vystytis sustot. Dabar viskas yra tiek pasikeitę, kad sunku ir suvokt, kaip ir kodèl tas buvo daroma senų senoveje (mot., $41 \mathrm{~m} .{ }^{33}$ ).

Tyrimo dalyvių teigimu, neipprastų sąmonès būsenų metu patirti išgyvenimai duoda atsakymus į klausimus, kurie, esant îprastai, kasdienei sąmonès būsenai, nesuvokiami, nepasiekiami: tau viskas tada pasidaro aišku (mot., 42 m.). Pakeistos sąmonès būsenos, anot tyrimo dalyvių, padeda izveikti sąmonès ar net informacijos ribotumus:

Pamatyt kitas realybes, kitas galimybes. Tai leidžia tau suvokti viską labiau realistiškai, kas čia dedasi aplink mus. O ne tik tikèti tuo, ką mums sako visuomenè, nepasitikèti visa ta propaganda (mot., $42 \mathrm{~m}$.). Aš tikiu, kad nèra viskas taip, yra parodoma. Galbūt čia yra tam tikras virusas įdètas. Galbūt dèl to (sąmonę keičianti substancija, - aut. past.) yra nelegalizuojama? Nes mąstantis žmogus pradeda mąstyti plačiau. Ir tai yra kvestionuojama - kaip tai dabar yra populiaru sakyti - tikrovę. O mes, kaip suprantam visi, tai tikrovè yra reliatyvus dalykas“; „Dèl to, prie savigydos, jo; [...] jisai pamato, kaip, tarkim, Vakaru medicina chemiją pumpuoja. Kalbu apie Prozac'a, kalbu apie antidepresantus, kalbu apie citramoną tą pati [...]. Tai viskas yra farmacija: tam, kad žmogus jaustųsi sveikas, ir [pauzè] vat, atseit, būtų sistemos dalis... (vyr., $28 \mathrm{~m}$.).

Taigi preliminarūs tyrimo rezultatai leidžia tarti, kad pakeistų, neiprastų sąmonès būsenų siekimas yra sudedamoji platesnès asmens pasaulèžiūros ar net tapatumo dalis, kuri galbūt ir lemia sieki praplèsti sąmonès ribas, ieškoti / siekti gilesnio savęs ir pasaulio pažinimo per sąmonę keičiančias praktikas. Sąmonès ribų plètimas traktuojamas kaip šio pasaulio ribotumo suvokimas, valdymo, socialinių santykių ir ideologijų, hierarchijos sistemų, įsipynusių i fizinę ir psichinę būtị, aptikimas, siekis iš jų išsivaduoti. Vadavimosi procesas siejamas su savojo vidinio "aš", tam tikru tiesos, „tikrumo“ ieškojimu.

\section{IŠVADOS}

Teorinio ir empirinio tyrimo rezultatai leidžia teigti, kad „sveikatos“ suvokimas, su sveikata ir vidiniu komfortu susijusios praktikos glaudžiai siejasi su asmens gyvenimo būdu, kultūrine aplin- ka. "Sveikatos", „ligos", "gydymo(si)“ sampratoms ir praktikoms ittaką daro lokalus sociokultūrinis kontekstas, istoriškai susiklosčiusios tradicijos, individuali pasaulèžiūra. 
Pakeistų, neiprastų sąmonės būsenų siekimas koreliuoja su asmens pasirinktu gyvenimo stiliumi, kasdienèmis praktikomis: tai gali būti medituojantis vienuolis, dvasinio kelio ieškotojas, vakarèlių mėgèjas ar neaiškios kilmès ligų kamuojamas chroniškas ligonis - visus juos sieja pakeistu, neịprastų sąmonès būsenų kaip sąmonès praplètimo ir (iš)gijimo galimybiu paieškos, vedančios prie pasaulio ir vidinio integralumo suvokimo.

Tyrimo rezultatai rodo, kad pozityvus netradicinių gydymo(si) būdų toleravimas iš dalies yra nusivylimo konvencine medicina, kuri siejama su farmacijos pramone ir apskritai - su „,siste-

\section{Literatūra ir nuorodos}

1 „Psichoaktyvios“ - tai psichiką veikiančios medžiagos. Tai gali būti kava, cukrus, tam tikros narkotinès medžiagos.

2 „Savigyda“ tekste traktuojama kaip laisva valia, remiantis turimomis tradicinès ir netradicinès medicinos žiniomis, naudojama gydomosi praktika, atliekama individualiu sprendimu, kad būtent tuo metodu asmuo gydo (ar sveikatina) savo fizinį, emocinį ar psichinį kūną.

3 Dar vadinamos ",tradicine, vakarietiška, alopatine" medicina.

4 „Pakeista“ (angl. changed, altered, taip pat sutinkamas pavadinimas altered states of mind), "neiprasta" sąmonè - tai sąmonès būsena, kuri gali būti pasiekiama natūraliais metodais (nemiga, badavimu, malda, ypač dideliu fiziniu ar emociniu krūviu) arba pasiekiama vartojant natūralias (gamtoje aptinkamas, ne cheminiu būdu gaminamas) psichoaktyvias substancijas.

${ }^{5}$ Reda Šatūnienė, Panku subkultūra - tapatumo bruožai. Kaunas: VDU, 2008.

6 Teorinis ir empirinis tyrimas sociokultūrinio ir emocinio "saugumo“ tema, atliktas $2011 \mathrm{~m}$. Michigano universitete pagal Ronald and Eileen Weiser Professional Development Award grantą.

7 Ramūnas Trimakas, Lietuviu liaudies medicina: etnografiniai ir folkloristiniai aspektai. XIX amžiaus ma" plačiąja prasme pasekmè. Toliau būna ieškoma alternatyvių metodų, gydymo(si) praktiku, kurios susijusios su asmeniniais issitikinimais, gyvenimo filosofija, sociokultūrine aplinka.

Galima teigti, kad susidomèjimas pakeistomis, neiprastomis sąmonès būsenomis yra susidomejjimo alternatyviomis sveiko būvio, savirealizacijos, saviraiškos galimybėmis pasekmė bei noras kvestionuoti dominuojančius sociokultūrinius modelius. Tai gali būti įvardinta kaip tam tikra kultūrinès rezistencijos forma, kritinè mus supančios aplinkos refleksija, normų, dogmų kvestionavimo pozicija. pabaiga - XX amžiaus pirmoji pusé. Vilnius: VU leidykla, 2008.

8 Veronika Gribauskaité, Ligu etiologijos Rytų Lietuvos ir Vakaru Baltarusijos kaime XIX a. pabaigoje - XX a. pirmojoje puseje. Liaudies kultūra. Vilnius: Lietuvos nacionalinis kultūros centras, 2008/6 (123), p. 26-30.

${ }^{9}$ Romualdas Petkevičius, Nerviniai sutrikimai ir jų gydymas Užpalių apylinkių XX-XXI a. tradicineje medicinoje. Lietuvos lokaliniai tyrimai. Etnologija. Lietuvos valsčiai. Užpaliai. Vilnius: Versmè, 2016, p. 1-44.

${ }^{10}$ Mircea Eliade, Shamanism: Archaic techniques of ecstasy. New York: Pantheon Books, 1964; Ake Hultkrantz, Ecological and phenomenological aspects of shamanism. Shamanism in Siberia. Budapest: Akademiai Kiad, 1978, p. 27-58; John Halifax, Shamanic voices. New York: Dutton, 1979; Michael Harner, Hallucinogens and shamanism. New York: Oxford University Press, 1973.

${ }^{11}$ Michael Winkelmann, Culture and Health: applying medical anthropology. San Francisco: John Wiley and Sons, 2009, p. 387.

12 Ten pat, p. 387.

13 Susan Greenwood, The Nature of Magic: An Anthropology of Consciousness. New York: Berg, 2005.

${ }^{14}$ Larson, p. 13-14, 17-18, 31. 
15 Larson, p. 3-4.

16 Michael Winkelmann, Culture and Health: applying medical anthropology. San Francisco: John Wiley and Sons, 2009, p. 11, 106-116, 5-6.

17 Ten pat, p. xviii-xix.

18 Vadovaujantis šia logika, gyvenimo būdas (stilius) gali nulemti mirti nuo širdies ligų (pvz., iki paryčių trunkantys vakarèliai su alkoholio gausa, paveikiantys atitinkamus organus), saldūs gèrimai mokyklose gali paskatinti su cukraus pertekliumi siejamas ligas, o rūkymas, kaip stiliaus ịvaizdis, gali lemti plaučių, gerklès susirgimus ir kt.

19 Winkelmann, p. 11, 106-116.

20 Remiamasi Arthur Kleinman, Medicine's symbolic reality: On a central problem in the philosophy of medicine. Inquiry, Vol. 16. I, London, NY: Routledge, 1973, p. 206-213; Arthur, Kleinman. Patients and healers in the context of culture: An exploration of the borderland between anthropology, medicine, and psychiatry. Berkeley: University of California, 1980, p. 27, 33. Michael Winkelmann, Culture and Health: applying medical anthropology. San Francisco: John Wiley and Sons, 2009, p. 8.

21 Pvz., depresija (sąlygiškai nauja), fibromalgija, ivairios organų disfunkcijos.

22 Michael Winkelmann, Culture and Health: applying medical anthropology. San Francisco: John Wiley and Sons, 2009, p. 14.

23 Ten pat, p. 15.
24 Ten pat, p. 140.

25 Ten pat, p. 393.

26 Ten pat.

27 Ten pat, p. 394.

28 LSD - haliucinoneginè medžiaga, atitinkamomis dozèmis vartota eksperimentinèje psichoterapijoje. Pvz., N. Chwelos, D. B. Blewett, C. M. Smith, A. Hoffer, Use of d-lysergic acid diethylamide in the treatment of alcoholism. Quarterly Journal of studies on Alcohol, Vol. 20. USA: Journal of Studies on Alcohol, Inc., 1959, p. 577-590. Prieiga per internetą: https://www.ncbi.nlm.nih.gov/ pubmed/13810249 [žiūrèta 201611 23].

29 Станислав Гроф. Области человечщзакого бесознательного: опыт исследований с помощю АСД. Москва: МТМ, 1994, с. 41-42.

30 Michael Gossop. Gyvenimas su narkotikais. Vilnius: Artlora, 2001, p. 227.

31 Rossi, Ernest Lawrence, In search of a deep psychobiology of hypnosis: Visionary hypotheses for a new millennium. American Journal of Clinical Hypnosis, Vol. 42(3-4). USA: Taylor\& Francis, 2000, p. 198. [ Paimta iš: Michael Winkelmann, Culture and Health: applying medical anthropology. San Francisco: John Wiley and Sons, 2009, p. 410].

32 Tyrimas tęsiamas.

33 Reda Šatūnienè, „Paribio“ patyrimai: pakeistų sąmonès būsenų reikšmė alternatyviuose gyvenimo modeliuose. Inter-Studia Humanitatis, Nr. 19. Šiauliai: ŠU leidykla, 2016, p. 108. 